\title{
Do long-acting $\beta_{2}$-adrenoceptor agonists enhance the anti- inflammatory effect of glucocorticoids in asthma?
}

\author{
A.J. Knox, Y.M. Zhu, L. Pang
}

Airway inflammation is a central feature in the pathophysiology of asthma and cytokine networks play a fundamental role in the chronic inflammatory process. Anti-inflammatory treatment with inhaled corticosteroids provides the mainstay of asthma management in conjunction with bronchodilator therapy. Short-acting $\beta_{2}$-adrenoceptor agonists have been used as bronchodilator treatment in asthma for decades and whilst these agents produce useful bronchodilatation through airway smooth muscle relaxation, concerns were raised for several years that they may have deleterious pro-inflammatory effects when given on their own. Short-acting $\beta_{2^{-}}$ agonists can cause a rebound increase in bronchial responsiveness after cessation of therapy [1] and regular salbutamol use can increase the early response to allergen [2]. A number of recent clinical studies, however, particularly with long-acting $\beta_{2}$-agonists have contradicted the established dogma that $\beta_{2}$-agonists are potentially harmful and may mask underlying inflammation [3-7]. Studies with longacting $\beta_{2}$-agonists have shown that when these drugs are given in conjunction with inhaled steroids, they produce beneficial effects on symptoms, airflow and asthma exacerbations [3-7]. Whilst these findings may reflect the fact that the best treatment for asthma is to combine an anti-inflammatory drug with a longacting airway smooth muscle relaxant, they raise the intriguing possibility that there is a beneficial interaction between long-acting $\beta_{2}$-adrenoceptor agonists and corticosteroids on part of the inflammatory process.

There are a number of in vitro studies which suggest potential anti-inflammatory actions of $\beta_{2^{-}}$ adrenoceptor agonists which may be complementary or even synergistic with the actions of corticosteroids and the manuscript in this issue by Korn et al. [8] adds further weight to this hypothesis. These investigators studied the effects of the long-acting $\beta_{2}$-agonist formoterol, and the corticosteroid budesonide, on secretion of granulocyte macrophage-colony stimulating factors (GM-CSF) and interleukin (IL)-8 secretion by primary bronchial epithelial cells in culture in response to the pro-inflammatory asthma mediator,

Division of Respiratory Medicine, Clinical Sciences Building, City Hospital, Nottingham, UK.

Correspondence: A.J. Knox, Division of Respiratory Medicine, Clinical Sciences Building, City Hospital, Nottingham, NG5 1PB, UK. Fax: 441158404771 tumour necrosis factor- $\alpha$ (TNF- $\alpha)$. GM-CSF is an important survival factor for eosinophils, whereas IL-8 is an important chemoattractant mainly for neutrophils. They found that budesonide reduced the amount of both factors by $\sim 40 \%$ when given alone. When formoterol was given alone it caused a reduction in GM-CSF levels to a similar extent as with budesonide, but also increased IL-8 levels by $50 \%$. However, when both formoterol and budesonide were given simultaneously, GM-CSF levels were lowered to basal levels suggesting an additive inhibitory effect. Furthermore, giving budesonide in addition to formoterol blocked the increase in IL- 8 that formoterol caused on its own. The combination of both agents therefore had an improved antiasthma profile causing an additive reduction of GM-CSF levels and a reduction in IL-8 production in this in vitro model. A number of studies in other in vitro models have similarly shown additive or synergistic effects of $\beta$ agonists and steroids given in combination, although there seemed to be slight differences in the response seen depending on the cell type studied.

Our own studies in human airway smooth muscle cells [9] show that both $\beta$-agonists and steroids given alone produce a reduction in eotaxin levels by $40-50 \%$ but when the drugs are given in combination the eotaxin production is almost abolished. As eotaxin is an important eosinophil chemoattractant, these findings taken in conjunction with the finding of KORN et al. [8] with GM-CSF, suggest that a combination of long-acting $\beta$-agonists and corticosteroids would be expected to reduce eosinophil recruitment and survival in the lung. There are similarities between the results of KoRN et al. [8] and our own results on human airway smooth muscle cells looking at IL-8 [10]. We found that corticosteroids, dexamethasone or fluticasone could reduce TNF- $\alpha$ stimulated IL-8 production by $\sim 50 \%$. Unlike KonN et al. [8], we did not find that TNF- $\alpha$ induced IL-8 release was potentiated by $\beta$-agonists given alone, though unstimulated IL-8 release was. Moreover, when the combination of a $\beta$-agonist and steroid were used to prevent TNF- $\alpha$ induced IL- 8 production, they had a marked synergistic effect suggesting that $\beta$-agonists had an inhibitory effect, which was only seen in the presence of a corticosteroid. The differences in responses between cell types may reflect differences in their $\beta$-receptor complements. These interactions do not seem to be confined to airway structural cells, since studies in mononuclear cells have also shown 
that salmeterol can enhance the inhibitory activity of dexamethasone on allergen-induced mononuclear cell activation [11].

A number of mechanistic explanations have been put forward to explain how $\beta$-agonists and steroids might interact to reduce inflammatory signals. One study in fibroblasts has suggested that $\beta$-agonists may promote translocation of the glucocorticoid receptor into the cell nucleus [12]. Whilst this mechanism may operate in some cells it would not explain the work by KonN et al. [8] as they showed no effect of glucocorticoid antagonists on the effect of formoterol. Similarly, we have been unable to show increased translocation of glucocorticoid receptor after $\beta$-agonist treatment in human airway smooth muscle cells [9]. Another possible explanation is an effect of $\beta$-agonists on the transcription factor nuclear factor-kappa B (NF-кB). A recent study in monocytic THP-1 (human promonocytic) cells stimulated with lipopolysacharide showed that $\beta$-agonists could inhibit TNF- $\alpha$ and IL-8 production and that the effect was related to increased cytoplasmic concentrations of the endogenous inhibitor of NF- $\mathrm{B}, \mathrm{I} \kappa \mathrm{B} \alpha$ (the inhibitory protein for NF$\kappa \mathrm{B})$, possibly through decreased IкB $\alpha$ degradation [13]. The effects of $\beta$-agonists in all of these cells appear to be mediated by $\beta_{2}$-adrenoceptors, although studies differ on whether protein kinase A is involved $[9,10]$.

There are several questions raised by these in vitro studies. Are the same effects seen with long- and short-acting $\beta$-agonists? Are these findings relevant to airway inflammation in vivo? With regard to the first question most of the studies showing a potential antiinflammatory effect of $\beta_{2}$-adrenoceptor agonists in vitro have shown that these effects are a class effect i.e. they are seen with both short- and long-acting drugs. This contrasts with the situation in vivo, where longacting drugs seem more effective than short-acting drugs. This may partially be explained by the fact that in vitro short-acting $\beta$-agonists are used in a way that mimics the effect of a long-acting $\beta$-agonist, i.e. the tissue preparation or cells being studied are continuously bathed with the drug, whereas in vivo, the pharmokinetics are such that $\beta_{2}$-receptor occupancy will fluctuate with short-acting drugs and there may be periods during the day where they lose their effect, particularly overnight.

Is there any evidence in support of anti-inflammatory effects of $\beta$-agonists in vivo? There seems to be little data to support this from studies with short-acting $\beta$-agonists [14] although a small reduction in eosinophils in induced sputum were seen in one study when short-acting $\beta$-agonists were combined with inhaled steroids [15]. With respect to the long-acting drugs, studies of salmeterol given alone have failed to show any reduction in inflammation in bronchial biopsies [16], thus emphasizing the fact that $\beta$-agonists given alone are probably not a suitable treatment for moderate asthma. Although few studies have set out to determine whether long-acting $\beta$-agonists can have anti-inflammatory effects when added to inhaled steroids, one study showed that introducing salmeterol caused a significant fall in the EG1 positive eosinophils in the lamina propria [17] therefore supporting an additional anti-inflammatory benefit. The fact that low dose budesonide plus formoterol had the same anti-inflammatory activity as high dose budesonide in another study would support this [18]. Further studies are required, however, to confirm or refute this.

In conclusion, an increasing volume of evidence suggests that beneficial interactions between longacting $\beta$-agonists and corticosteroids may occur in vitro in a number of airway cells relevant for asthma. It is tempting to speculate that these interactions may be important in the reduction of exacerbations and improvement in asthma that occurs in clinical studies when these agents are combined, although further evidence is needed. Nevertheless, combined treatment with long-acting $\beta$-agonists and inhaled corticosteroids is likely to provide the mainstay of asthma management for the forseeable future.

Acknowledgements. The authors would like to thank R. Small for secretarial assistance.

\section{References}

1. Vathenen AS, Knox AJ, Higgins BG, Britton JR, Tattersfield AE. Rebound increase in bronchial responsiveness after treatment with inhaled terbutaline. Lancet 1988; 1: 554-558.

2. Cockroft DW, McParland CP, Britto SA, Swystun VA, Rutherford BC. Regular inhaled Salbutamol and airways responsiveness to allergen. Lancet 1993; 342: $833-837$.

3. Greening AP, Ind PW, Northfield M, Shaw G. Added salmeterol versus higher dose corticosteroid in asthma patients with symptoms on existing inhaled corticosteroid. Lancet 1994; 344: 219-224.

4. Woolcock A, Lundback B, Ringdal N, Jacques LA. Comparison of addition of salmeterol to inhaled steroids with doubling of the dose of inhaled steroids. Am J Respir Crit Care Med 1996; 153: 1481-1488.

5. Pauwels RA, Lofdahl CG, Postma D, et al. Effect of inhaled formoterol and budesonide on exacerbations of asthma. N Engl J Med 1997; 337: 1405-1411.

6. Wilding PM, Clark JT, Coon S, et al. Effect of long term treatment with salmeterol on asthma control: a double blind, randomised crossover study. BMJ 1997; 314: $1441-1446$.

7. Van Noord JA, Schreurs AJ, Mol SJ, Mulder PG. Addition of salmeterol versus doubling the dose of fluticasone proprionate in patients with mild to moderate asthma. Thorax 1999; 54: 207-212.

8. Korn HS, Jerre A, Brattsand R. Effects of formoterol and budesonide on GM-CSF and IL-8 secretion by triggered human bronchial epithelial cells. Eur Respir $J$ 2001; 17: 1070-1077.

9. Pang L, Knox AJ. Synergistic inhibition by $\beta_{2^{-}}$ agonists and corticosteroids on tumour necrosis factor alpha induced interleukin-8 release from cultured human airway smooth muscle cells. $\mathrm{Am}$ J Respir Cell Mol Biol 2000; 23: 79-85.

10. Pang LH, Knox AJ. Regulation of TNF $\alpha$ induced eotaxin release from cultured human airway smooth muscle cells by $\beta_{2}$-agonists and corticosteroids. FASEB J 2001; 15: 261 - 269. 
11. Odera S, Vestri M, Testi R, Rossi GA. Salmeterol enhances the inhibiting activity of dexamethasone on allergen-induced blood mononuclear cell activation. Respiration 1998; 65: 199-204.

12. Eickleberg OM, Roth R, Lorx $\mathrm{V}$, et al. Ligandindependent activation of the glucosteroid receptor by (2-adrenergic receptor agonists in primary human lung fibroblasts and vascular smooth muscle cells. $J$ Biol Chem 1999; 274: 1005-1010.

13. Farmer P, Pugin J. $\beta$ adrenergic agonists exert their anti-inflammatory effects in monocytic cells through the IкB/NF-кB pathway. Am J Physiol Lung Cell Mol Physiol 2000; 279: L675-L682.

14. Aldridge RE, Hancox RJ, Robin Taylor D, et al. Effects of terbutaline and budesonide on sputum cells and bronchial hyperresponsiveness in asthma. Am J Respir Crit Care Med 2000; 161: 1459-1464.

15. Dents FL, Bancalari L, Bacci E, et al. Effect of a single dose of salmeterol on the increase in airway eosin ophils induced by allergen challenge in asthmatic subjects. Thorax 1999; 54: 622-624.

16. Roberts JA, Bradding P, Britten KM, et al. The long acting beta-2 agonist salmeterol xinaforte: effects on airway inflammation in asthma. Eur Respir J 1999; 14 : $275-282$.

17. Li X, Ward C, Thien F, et al. An anti-inflammatory effect of salmeterol, a long acting beta 2 agonist assessed in airway biopsies and bronchoalveolar ravage in asthma. Am J Respir Crit Care Med 1999; 160: $1493-1499$.

18. Kips JC, O'Connor BJ, Inman MD, Svensson K, Pauwels RA, O'Byrne PM. A long term study of the anti-inflammatory effect of low dose budesonideplus formoterol versus high dose budesonide in asthma. Am J Respir Crit Care Med 2000; 161: 996 1001 . 